\title{
Targeted therapy against cancer stem cells (Review)
}

\author{
TAO YANG $^{1}$ and KIERA RYCAJ ${ }^{2}$ \\ ${ }^{1}$ Research Center for Translational Medicine, Shanghai East Hospital, Tongji University School of Medicine, \\ Shanghai 200120, P.R. China; ${ }^{2}$ Department of Molecular Carcinogenesis, The University of \\ Texas MD Anderson Cancer Center, Smithville, TX 78957, USA
}

Received July 18, 2014; Accepted April 21, 2015

DOI: $10.3892 / \mathrm{ol} .2015 .3172$

\begin{abstract}
Research into cancer stem cells (CSCs), which have the ability to self-renew and give rise to more mature (differentiated) cancer cells, and which may be the cells responsible for the overall organization of a tumor, has progressed rapidly and concomitantly with recent advances in studies of normal tissue stem cells. CSCs have been reported in a wide spectrum of human tumors. Like normal tissue stem cells, CSCs similarly exhibit significant phenotypic and functional heterogeneity. The ability of CSCs to self-renew results in the immortality of malignant cells at the population level, whereas the ability of CSCs to differentiate, either fully or partially, generates the cellular hierarchy and heterogeneity commonly observed in solid tumors. CSCs also appear to have maximized their pro-survival mechanisms leading to their relative resistance to anti-cancer therapies and subsequent relapse. Studies in animal models of human cancers have also provided insight into the heterogeneity and characteristics of CSCs, helping to establish a platform for the development of novel targeted therapies against specific CSCs. In the present study, we briefly review the most recent progress in dissecting CSC heterogeneity and targeting CSCs in various human tumor systems. We also highlight a few examples of CSC-targeted drug development and clinical trials, with the ultimate aim of developing more effective therapeutic regimens that are capable of preventing tumor recurrence and metastasis.
\end{abstract}

Correspondence to: Dr Tao Yang, Research Center for Translational Medicine, Shanghai East Hospital, Tongji University School of Medicine, 150 Jimo Road, Shanghai 200120, P.R. China E-mail: mryangtao2005@yahoo.com

Dr Kiera Rycaj, Department of Molecular Carcinogenesis, The University of Texas MD Anderson Cancer Center, Science Park, Smithville, TX 78957, USA

E-mail:krycaj@mdanderson.org

Key words: cancer stem cell, targeted therapy, chemotherapy resistance, tumor recurrence, matastasis, microRNA

\section{Contents}

1. Introduction

2. Leukemia stem cells and targeted therapy

3. Breast CSCs and targeted therapy

4. Prostate CSCs and targeted therapy

5. Glioma stem cells and targeted therapy

6. Colorectal stem cells and targeted therapy

7. Targeted therapy against other CSCs

8. Conclusion

\section{Introduction}

The etiology of cancer development and the molecular mechanisms underlying conventional therapy-resistant progression, metastasis and recurrence are poorly understood, resulting in numerous patients who still fail therapy. Cancer is recognized as a heterogeneous disease, an intrinsic attribute that contributes to therapy failure. Emerging evidence from a number of tumor systems has revealed the existence of distinct subpopulations of stem-like cancer cells, termed cancer stem cells (CSCs), that possess clonal long-term repopulation and self-renewal capacities. Theories suggest that both genetic and CSC models of cancer contribute to this tumor heterogeneity. With stemness as a guiding principle, data generated from advanced genome sequencing, epigenetics and the influences of non-tumor cell elements in the tumor microenvironment could potentially be combined in order to reveal the underlying mechanisms of tumor heterogeneity (1). As a fraction of this heterogeneous population, CSCs are inherently resistant to cytotoxic chemotherapy and radiation, and evidence has linked stemness to prognosis and therapy failure (2). This suggests that specifically identifying how CSC involvement is linked to tumor initiation, progression, metastasis and therapy resistance may lead to a more perceptive approach of developing therapeutics to target this cell population. Despite the vast complexity observed within a tumor, there are fundamental attributes of CSCs that may be exploited in drug development. A number of potential CSC therapeutic targets have been identified, including the ABC superfamily, anti-apoptotic factors, detoxifying enzymes, DNA repair enzymes and distinct oncogenic cascades. However, the key stem cell attribute of self-renewal, which ensures the continuation of the stemness heritage, has recently drawn considerable attention, possibly representing 
a new paradigm in cancer therapy. Below, we summarize the recent advances in CSC studies in various tumor systems, highlight efforts in developing targeted therapies against specific CSCs, discuss the mechanisms underlying CSC response and resistance to these therapies, and explore the possibilities of moving CSC-targeted therapy to the clinic.

\section{Leukemia stem cells and targeted therapy}

Acute myeloid leukemia (AML) is a heterogeneous disease that harbors numerous cell subpopulations with diverse genetic abnormalities and clinical features. Despite high remission rates following therapy, many patients with AML do not survive 5 years after their initial diagnosis. The main cause of treatment failure may be insufficient eradication of a particular subpopulation of leukemia stem-like cells (LSCs), which may be responsible for relapse by giving rise to more differentiated leukemic progenitors. Gene signatures specific to either LSCs in AML or normal hematopoietic stem cells (HSCs) have been developed, and were demonstrated to share a set of genes that defines a common stemness program. These stem cell-related gene signatures are significant independent predictors of patient survival in large clinical databases (2). Determinants of stemness influence the clinical outcome of AML, demonstrating that LSCs are clinically relevant and are not artifacts of xenotransplantation. LSCs from diagnostic patient samples are genetically diverse, and reconstruction of their genetic ancestry reveals that multiple subclones of LSCs are related through a complex branching evolutionary process (3). The discovery that specific genetic events influence the frequency of leukemia-initiating cells (LICs) and that genetically distinct LICs evolve through a complex evolutionary process indicates that genetic and functional heterogeneity are closely connected. AML LSCs have been reported to bear the $\mathrm{CD} 34^{+} \mathrm{CD} 38^{-}$marker profile of normal HSCs $(4,5)$. Xenotransplantation studies confirm the general rarity of LSCs, but also reveal a more complex heterogeneity of these cells (6). Despite their similarities, AML LSCs may not be derived from normal HSCs as initially hypothesized. Furthermore, clonal evolution and CSC-directed development may not be mutually exclusive, and the two mechanisms may combine to create tumor cell heterogeneity (7). In a hierarchical model, the most primitive CSCs develop into more mature tumor progenitors, which then develop into cells which are far more differentiated but have lower tumorigenicity. These functionally divergent tumorigenic subsets may be dissected by serial transplantations coupled with clonal tracking (5). Conversely, multiple CSC subsets in a tumor may exist in a tumorigenic pool of undifferentiated cells, with various origins, and with no association with each other in terms of lineage. In breast cancer, the $\mathrm{CD} 44^{+} \mathrm{CD} 24^{-}$cell population is enriched with progenitor cells and the $\mathrm{CD} 24^{+}$population is luminally differentiated. However, in certain tumors there is no correlation in lineage between $\mathrm{CD}_{24}^{-}$and $\mathrm{CD} 24^{+}$epithelial cells as the two populations harbor different genetic alterations (8). Similarly, CD133 ${ }^{+}$ and CD133- glioma cells may have different cells-of-origin (9). Evidence reveals that the primary tumor genotypes determine the overall phenotypes of tumor progenitors (10). It is possible that more mature tumor-initiating cells (TICs) derived from primitive CSCs sustain secondary genetic hits and in turn become new CSCs, going on to develop independently of the original CSCs. Thus, hierarchical tumor-initiating populations and independently evolving tumorigenic clones may synergistically contribute to cancer cell heterogeneity.

Despite the absence of specific LSC markers, cell surface adhesion receptors including CD44, IL3R and the immunoglobulin mucin TIM-3, which are differentially expressed between normal HSCs and LSCs, are currently exploited for monoclonal antibody therapeutics in human AML. Treatment with antibodies against these molecules has demonstrated a notable decrease in leukemogenicity and eradication of CSCs in mice, suggesting promise in future clinical trials (11-13). Additionally, differences in gene expression, specifically in microRNAs (miRNAs) between LSCs and bulk leukemia, have been examined in order to identify targets for anti-LSC therapy. In AML, abnormal miRNA expression patterns are correlated with tumor classification, cytogenetic status, molecular abnormalities and prognosis (14). Deregulated expression of miRNAs is associated with uncontrolled self-renewal and/or therapy resistance $(15,16)$. In a previous study (17), miRNA expression patterns were compared in $\mathrm{CD} 34^{+} \mathrm{CD} 38$ HSCs, CD $34^{+} \mathrm{CD} 38^{-}$LSCs and $\mathrm{CD} 34^{+} \mathrm{CD} 38^{+}$hematopoietic progenitors, all derived from bone marrow (BM) specimens from the same patients. Results identified that miR-126 was highly expressed in HSCs and increased in LSCs compared with the progenitors. High miR-126 expression in AML was correlated with poorer survival, increased chance of relapse and the expression of genes present in LSC/HSC signatures. Notably, attenuating miR-126 expression in AML cells reduced in vitro cell growth by inducing apoptosis, but did not affect the viability of normal BM cells. These results highlight miR-126 as a potential novel therapeutic target to eradicate LSCs and improve AML outcome (17).

In T-cell acute lymphoblastic leukemia (T-ALL), loss of Pten tumor suppressor frequently occurs and is associated with therapeutic resistance. The mTOR inhibitor rapamycin suppressed leukemia development in Pten null pre-leukemic mice but was not capable of eliminating LICs following the onset of T-ALL (18). Notably, LICs in Pten null T-ALL models are actively proliferating, suggesting that LICs may be sensitive to cell cycle inhibitors. Indeed, combinatorial treatment with the Aurora kinase inhibitor VX-680 and the bromodomain inhibitor JQ1 of Pten null T-ALL mice induced robust elimination of leukemia blasts and significantly diminished LICs (18). These results highlight potent synthetic lethality of co-targeting the PI3K pathway and cell cycle in Pten null T-ALL LSCs, suggesting a potentially novel therapeutic approach to treat human leukemia.

\section{Breast CSCs and targeted therapy}

In human breast cancer, analyses reveal a high degree of genetic heterogeneity within and between distinct tumor cell populations that are defined based on markers of cellular phenotypes (8). Accumulating evidence supports the existence of breast cancer stem cells (BCSCs), which have the capacity to self-renew and divide indefinitely, and which are resistant to conventional therapies (19). Therefore, eradication of BCSCs is theoretically necessary to cure the disease. In previous studies, a combination of surface markers was employed to purify 
out mammary basal stem cells $\left(\mathrm{CD} 49 \mathrm{f}^{\text {hi }}\right.$ but epithelial cell adhesion molecule (EpCAM)-negative), luminal progenitors $\left(\mathrm{CD} 4 \mathrm{f}^{+} \mathrm{EpCAM}^{+}\right)$and mature luminal cells $\left(\mathrm{CD} 49 \mathrm{f}^{-} \mathrm{EpCAM}^{+}\right)$ from normal mammary tissue and preneoplastic specimens in individuals heterozygous for the BRCAl mutation, which is clinically linked to the development of basal-like breast cancers $(19,20)$. Notably, the BRCAl-mutant samples exhibited a significant reduction in basal stem cells but a significant increase in luminal progenitor cells. This suggests that an aberrant luminal progenitor population may represent the BCSCs in $B R C A 1$-associated basal-like breast tumors (20). Independent studies in mouse models have deleted BRCAl in basal stem or luminal progenitor cells and confirmed that only BRCAI deletion in the luminal progenitor compartment phenotypically and histologically recapitulates human basal-like breast cancers (21). Notably, mammary epithelial cells derived from $B R C A I^{\mathrm{mut} /+}$ patients give rise to tumors with increased basal differentiation compared with $B R C A 1^{+/+}$cells (10), suggesting that specific genetic mutations determine the phenotypic outcome of progenitor cells in tumor development.

The characterization of key signaling pathways that regulate the formation of BCSCs may have implications in the development of CSC-targeted therapies. For instance, the focal adhesion kinase (FAK) and its associated signaling pathways appear to play a significant role in the progression of breast cancer in vivo (22). Genetic inactivation of FAK leads to defective BCSCs and depletion of the CSC pool in vivo, leading to the suppression of mammary tumorigenesis (22). These results suggest that FAK inhibitors may be effective in eliminating BCSCs. Since residual breast cancer is enriched in BCSCs, which possess intrinsic chemoresistance $(23,24)$, therapeutics that target BCSCs may help overcome drug resistance and prevent recurrence.

Notch and other major developmental pathways, including Wnt and Hedgehog (Hh), are considered to be central to the maintenance of BCSCs, and therefore represent potential targets for BCSC-directed therapy (25). The roles of Notch receptors in stem cell activity in breast cancer cell lines and primary human tumor samples have been assessed. The results revealed that pharmacological or genetic inhibition of Notch1 or Notch4 reduced stem cell activity in vitro and reduced tumor formation in vivo, with Notch4 inhibition producing a more robust effect with a complete inhibition of tumor regeneration (26). This and other successful preclinical data based on Notch-targeted therapies have led to the first clinical trial (27). In this study, treatment with gamma secretase inhibitor (GSI) reduced BCSCs in patient-derived breast tumorgrafts via inhibition of the Notch pathway. GSI also enhanced the efficacy of docetaxel in preclinical studies. A subsequent clinical trial utilizing relevant doses of the two drugs resulted in decreased CD44 ${ }^{+} \mathrm{CD} 24^{-}, \mathrm{ALDH}^{+}$ and mammosphere-forming efficiency in patient tumors. This was the first clinical trial to establish a safe and potentially efficacious combination of a GSI in combination with docetaxel chemotherapy in patients with advanced breast cancer. However, a residual BCSC subpopulation remained unaffected by inhibition of the Notch signaling pathway in most tumors in the tumorgraft studies. Future molecular analysis of this particular population may help identify pathways of treatment resistance, potentially leading to the development of a 'cocktail' of BCSC inhibitors in order to improve treatment (27).

\section{Prostate CSCs and targeted therapy}

Homeobox gene $N k x 3.1$ is a known regulator of prostate epithelial differentiation, marking a luminal stem cell population that functions during prostate regeneration. It is an efficient target for oncogenic transformation in prostate cancer (PCa). Castration-resistant $\mathrm{Nkx} 3.1^{+}$cells (CARNs) in the absence of androgen are bipotential and self-renew in vivo; they may serve as a cell-of-origin for PCa (28). Deletion of the androgen receptor $(A R)$ in CARNs affects their ability to serve as cells-of-origin for $\mathrm{PCa}$ in a context-dependent manner, since Pten deletion in combination with Kras activation results in aggressive cancer in the absence of androgen administration in both normal and $A R$-deleted CARNs, whereas deletion of Pten solely in $A R$-deleted CARNs does not result in tumor formation $(28,29)$. Notably, castration in mice causes prostatic epithelial cells to undergo epithelial-to-mesenchymal transition (EMT), which appears to be associated with the development of castration resistance (30). Also of interest, deletion of Pten in the cytokeratin-5 cellular compartment promotes basal-to-luminal differentiation and development of invasive PCa (31), suggesting that this tumor suppressor normally plays a critical role in maintaining the identity of prostatic basal epithelial cells.

In $\mathrm{PCa}$, the prostate-specific antigen (PSA)-negative or low-expressing $\left(\mathrm{PSA}^{-/ l o}\right)$ cell population harbors self-renewing cells that fulfill all criteria defining prostate CSCs (PCSCs) (32). $\mathrm{PSA}^{+}$cells in untreated $\mathrm{PCa}$ are highly proliferative, contributing to tumor mass, whereas $\mathrm{PSA}^{-/ l o} \mathrm{PCa}$ cells are notably tumorigenic and metastatic (32). Significantly, $\mathrm{PSA}^{+}$ cancer cells are plastic since constitutive overexpression of Nanog or persistent castration in vitro and in vivo induces their de-differentiation into $\mathrm{PSA}^{-/ 10}$ cells $(32,33)$. Taken together, these data suggest that various subsets of PCSCs as well as cells-of-origin of PCa may all be encompassed in the PSA-/lo pool. In clinical settings, it is of great significance to determine which cells mediate castration resistance and initiate metastatic activity (34). Human PCa cells, when orthotopically implanted in immunodeficient mice, exhibit more extensive metastasis than when ectopically implanted (35). Therefore, it should be practically significant to perform metastasis assays and to identify metastatic PCSCs by performing orthotopic implantations.

From a drug development perspective, understanding how PCSCs are regulated at the molecular level is likely to provide essential clues in identifying potentially novel therapeutic targets. In this regard, Nanog, a homeodomain transcription factor essential for embryonic stem cell self-renewal and pluripotency, was demonstrated to play a critical role in positively regulating properties of PCSCs $(33,36)$. Thus, knockdown of endogenous Nanog inhibits PCa as well as other cancer development by restricting CSC-associated activities (36). By contrast, inducible expression of Nanog is sufficient to confer PCSC properties and to promote castration-resistant PCa development (33). These studies suggest that genetic manipulation of Nanog may represent an effective method in developing novel therapeutics to target PCSCs. At the same time, miRNAs have emerged as critical regulators of PCSCs. In six populations of PCa stem/progenitor cells that possess distinct tumorigenic properties, multiple miRNAs were identified to be commonly 
and differentially expressed; namely, four miRNAs (miR-34a, let-7b, miR-106a and miR-141) were underexpressed, and two miRNAs (miR-301 and miR-452) were overexpressed in the tumorigenic subsets compared with the corresponding marker-negative subpopulations (37). Among them, the expression patterns of miR-34, let-7b, miR-141 and miR-301 were further confirmed in the $\mathrm{CD} 44^{+}$human primary $\mathrm{PCa}$ samples. A subsequent study demonstrated that miR-34a, as a direct target of $\mathrm{p} 53$, functions as a potent negative regulator of PCSC and PCa growth/metastasis by directly repressing CD44 (34). Similarly, let-7 also demonstrates suppressive effects on PCa development (37). Furthermore, differential mechanisms of action between let-7 and miR-34a on the cell cycle were observed, with miR-34a mainly inducing G1 cell cycle arrest followed by cell senescence and let-7 inducing G2/M arrest (34,37). Finally, miR-128 functions as a tumor suppressor in PCa by limiting CSC properties mediated by BMI-1 and other central stem cell regulators (38). In summary, this study revealed that different microRNAs collaboratively regulate various functional aspects of PCSCs, laying a scientific foundation for developing miRNA-based anti-PCSC therapeutics.

Skp2 E3 ligase is overexpressed in a number of human cancers and plays a significant role in cell cycle progression, senescence, metabolism, cancer progression and metastasis. In a study employing genetic and pharmacological approaches, it was revealed that Skp2 also positively regulated CSC populations and possessed self-renewal ability. With a focus on PCa, the group identified a specific Skp2 inhibitor that exhibited potent antitumor activities in various animal models and cooperated with chemotherapeutic agents to reduce cancer cell survival. This study therefore provides experimental evidence that Skp2 may represent a promising target for inhibiting CSC self-renewal (39).

\section{Glioma stem cells and targeted therapy}

Glioblastoma (GBM) has been strongly associated with the presence of CSCs (40). CSCs in GBM have been enriched using several cell surface molecules including CD133, epidermal growth factor receptor (EGFR) and CD44 $(40,41)$. Although stem cell gene expression patterns are associated with $\mathrm{CD} 133^{+} \mathrm{GBM}$ cells, tumorigenic cells are observed in $\mathrm{CD} 133^{+}$and $\mathrm{CD} 133^{-}$cell populations, which may have different cells-of-origin, suggesting that human malignant gliomas are extremely heterogeneous and may harbor numerous pools of self-renewing glioma stem cells (GSCs) $(9,42,43)$. Although the role of CD133 as a CSC marker is controversial to a certain degree, previous data suggest that CD133 is essential for GSC maintenance as disruption of CD133 expression by short hairpin RNA in human GBM neurospheres impairs the self-renewal and tumorigenic capacity of the neurosphere cells (44). Thus, therapy against CD133 may represent a promising therapeutic strategy for patients with GBM.

Highly tumorigenic GSCs isolated from the tumor xenografts of human GBM reveal unique energy metabolic characteristics, including low mitochondrial respiration, increased glycolysis for adenosine triphosphate generation and preference for hypoxia to maintain their stemness and tumor-forming capacity (45). Mitochondrial depression in the
GSCs occurs mainly at complex II of the electron transport chain with a downregulation of the succinate dehydrogenase subunit $\mathrm{B}$, inducing deregulation of hypoxia-inducible factors. Under hypoxia, GSCs are resistant to conventional chemotherapeutic agents including carmustine and temozolomide, but are highly sensitive to glycolytic inhibition (46). Amplification of the EGFR gene is common in GBM, and numerous GBMs express EGFRvIII, an altered form of the EGFR gene, which correlates with a poorer prognosis (47). A previous study reveals that EGFRvIII is highly co-expressed with $\mathrm{CD} 133$ and that $\mathrm{EGFRvIII} / \mathrm{CD} 133^{+}$defines the population of GSCs with the strongest capacity for self-renewal and tumor initiation (48). Notably, elimination of the EGFRvIII $/ \mathrm{CD} 133^{+}$population using a bispecific antibody reduced the tumorigenicity of implanted tumor cells more effectively than any reagent directed against a single epitope (48). This study demonstrates that a mutated oncogene may have CSC-specific expression and may be used to specifically target this population.

\section{Colorectal CSCs and targeted therapy}

Substantial progress has been made in the treatment of colon cancer. However, the metastatic disease remains largely incurable. Lineage tracing and transplantation assays have demonstrated the existence of phenotypically distinct populations of tumorigenic and non-tumorigenic cells in a number of human cancers (4). In colorectal cancer (CRC), the tumorigenic population exhibits stem cell properties, mediates metastasis and is treatment-resistant. These cells are characterized by the expression of markers including LGR5 and CD44, downstream targets of Wnt signaling, a pathway deregulated in almost all CRCs (49). These colon cancer stem-like cells also express the polycomb gene $B M I-1$, a gene that ultimately regulates genes involved in stem cell behavior. BMI-1 expression has been associated with aggressive colon cancer and poor patient outcome, and also mediates chemotherapy and radiation resistance (50). One notable study demonstrates success in specifically exploiting stem cell self-renewal as a therapeutic target, thereby providing the basis for a new therapeutic approach in CRC treatment (51). Data from this study demonstrate that tumor formation and human colorectal CSC function are dependent on the self-renewal regulator BMI-1. Downregulation of BMI-1 reduced human colorectal cancer growth and inhibited the ability of colorectal CSCs to self-renew, resulting in decreased tumorigenic potential. In addition, the BMI-1 inhibitor irreversibly impaired colorectal CSCs (51). Following the success of this study, future studies should focus on additional molecules and gene signatures that underlie stemness.

High Wnt activity functionally defines colon CSCs (49). Drug resistance of colon CSCs may be circumvented by pre-treatment with histone deacetylase (HDAC) inhibitors, which change the level of pro- and anti-apoptotic molecules and thereby facilitate cell death. Notably, treatment with HDAC inhibitors results in a strong reduction of typical Wnt targets, including LGR5, and demonstrates strong induction of differentiation (49). HDAC inhibitors therefore pose a novel means to sensitize colon CSCs to chemotherapy by enhancing their differentiation. Conversely, CD44 could be a robust 
marker for colorectal CSCs, and osteopontin secreted from macrophages may function as a ligand for CD44 to maintain CSC properties (52). The cellular prion protein ( $\mathrm{PrPc}$ ) was shown to be co-expressed with CD44 in colorectal CSCs. The $\mathrm{PrPc}^{+}$subpopulation within the $\mathrm{CD} 44^{+}$cell population exhibited high liver metastatic capability. PrPc promoted EMT via the extracellular signal-regulated kinase 2 pathway, rendering CSCs capable of metastasis (52). Monoclonal antibodies against PrPc significantly inhibited the tumorigenicity and metastasis of colorectal CSCs in models of orthotopic transplantation. Moreover, $\mathrm{PrPc}$ may be a biomarker for circulating CRC CSCs and a potential target for cancer therapy (52). Additionally, colon cancer cells were revealed to not only overexpress proteinase-activated receptor $2\left(\mathrm{PAR}_{2}\right)$ but also secrete the proteinases, which cleave and activate $\mathrm{PAR}_{2}$ selectively (53). An autocrine loop of $\mathrm{PAR}_{2}$ and its proteinases may play a significant role in the maintenance of colorectal CSCs. Knockdown of $\mathrm{PAR}_{2}$ not only significantly attenuated sphere formation in vitro, but also inhibited CD133 expression. 5-fluorouracil induced greater apoptosis in $\mathrm{CD} 133^{+}$cells than CD133- cells after $\mathrm{PAR}_{2}$ was knocked down, suggesting that $\mathrm{PAR}_{2}$ signaling may be required by $\mathrm{CD} 133^{+} \mathrm{CRC}$ cells, and $\mathrm{PAR}_{2}$ may act as another potential target for targeted therapy against colorectal CSCs (53).

\section{Targeted therapy against other CSCs}

In hepatocellular carcinoma (HCC), CD24 is a functional marker for liver CSCs and was observed to drive genesis of TICs through STAT3-mediated Nanog regulation (54). In addition, TICs capable of tumor initiation and self-renewal in the presence of chemotherapeutic agents may also be enriched in terms of CD47 sorting. CD47 ${ }^{+} \mathrm{HCC}$ cells preferentially secreted cathepsin S (CTSS), which regulates liver TICs via the CTSS/PAR 2 loop. Suppression of CD47 by the Morpholino approach suppressed the growth of HCC in vivo and exerted a chemosensitization effect through the blockade of CTSS/PAR signaling (55). These findings shed light on the cascades of CD24 and CD47 in liver TICs, which may provide promising therapeutic targets for $\mathrm{HCC}$ patients.

In head and neck cancer, aldehyde dehydrogenase (ALDH) may be used as a marker to enrich CSCs (56). In murine models of melanoma D5 and squamous cell cancer SCC7, enriched CSCs are immunogenic and significantly more effective as an antigen source in inducing antitumor immunity than unsorted tumor cells or purified non-CSCs $(56,57)$. Likewise, a high expression level of ALDH (ALDH $\left.{ }^{\text {hi }}\right)$ is also a specific marker for the CSC population in human head and neck squamous cell carcinoma (HNSCC). When $\mathrm{ALDH}^{\text {hi }} \mathrm{CSC}$ and cells with low levels of ALDH $\left(\mathrm{ALDH}^{\mathrm{lo}}\right)$ were isolated from HNSCC, and effector T and B cells and dendritic cells (DCs) were generated from the patient peripheral blood mononuclear cells, immunization of DCs with $\mathrm{ALDH}^{\text {hi }} \mathrm{CSCs}$ was demonstrated to sensitize $\mathrm{T}$ and $\mathrm{B}$ cells to produce significantly higher amounts of interferon- $\gamma$, granulocyte-macrophage colony-stimulating factor, $\operatorname{IgM}$ and $\operatorname{IgG}$, respectively, as compared with immunization with $\mathrm{ALDH}^{\text {lo }}$ cells (57). These observations indicate that immunization of DCs with $\mathrm{ALDH}^{\text {hi }} \mathrm{CSC}$ boosts cellular and humoral immunity against head and neck cancer, which may help develop novel approaches for head and neck cancer treatment by utilizing an autologous CSC-based vaccine to selectively and immunologically target CSCs.

Drug resistance in non-small cell lung cancer (NSCLC) and small cell lung cancer (SCLC) may be attributable to the persistence of a subpopulation of CSCs that exhibit multiple drug resistance. For example, CD133+ NSCLC cells are more tumorigenic than CD133- cells and express genes involved in stemness, adhesion, motility and drug efflux (58). In a previous study, CD133 expression in SCLC was correlated with chemoresistance and increased tumorigenicity in vitro and in vivo, as well as increased expression of $\mathrm{Akt} / \mathrm{PKB}$ and Bcl-2. In CD133+ SCLC cells, an increased expression of the mitogenic neuropeptide receptors for gastrin-releasing peptide and arginine vasopressin was noted (59). These cells demonstrated increased sensitivity to the growth inhibitory and proapoptotic effects of a novel broad-spectrum neuropeptide antagonist. These results indicate that neuropeptide antagonists preferentially target chemoresistant $\mathrm{CD} 133^{+}$cells with CSC characteristics in SCLC, therefore offering a potentially novel therapy for resistant SCLC (59).

\section{Conclusion}

Currently, most anti-cancer therapeutics primarily target either differentiated or proliferating cancer cells, and may not be effective against CSCs that are relatively undifferentiated and mostly quiescent. Emerging evidence indicates that a number of conventional anti-cancer therapies may actually enrich CSCs, possibly as a result of elimination of differentiated and proliferative cancer cells as well as by inducing de-differentiation or transdifferentiation $(60,61)$. Notably, CSCs and non-CSCs were observed to reciprocally regulate or protect each other. In GBM, GSCs that express high levels of mutated EGFR produce interleukin- 6 and leukemia inhibitory factor, which activate gp130 and wild-type EGFR in the adjacent non-GSCs within glioma tissue (43). Conversely, non-CSCs in colon cancers protect CSCs from the toxic effects of chemotherapeutic drugs (62). Taken together, these observations highlight the benefit of targeting undifferentiated CSCs as well as differentiated non-CSCs. By synchronously targeting tumorigenic and non-tumorigenic cells, cancer cell heterogeneity and plasticity could theoretically be eradicated (63). In clinical treatment, non-tumorigenic tumor cells are treated relatively easily by most standard-of-care therapies, whereas the current obstacle is to identify novel therapeutic agents that specifically target undifferentiated or dormant CSCs, which should be identifiable by exploiting CSC-specific phenotypic or genetic features.

\section{Acknowledgements}

The authors are grateful to Dr. Dean Tang for offering notable advice on constructing this review and for critically proofreading and editing the manuscript. The study was financially supported by the National Natural Science Foundation of China (grant no. 81372750), Shanghai Natural Science Foundation of China (grant no. 12ZR1425200), the Science and Technology Fund of Shanghai Pudong (grant no. PKJ2014-Y10) and the Scientific Research Foundation for the Returned Overseas Chinese Scholars from the State Education Ministry of China (grant no. 2013-1792) to TY. KR was supported by an NIH postdoctoral training grant (T32 CA009480). 


\section{References}

1. Kreso A and Dick JE: Evolution of the cancer stem cell model. Cell Stem Cell 14: 275-291, 2014.

2. Eppert K, Takenaka K, Lechman ER, Waldron L, Nilsson B, van Galen P, Metzeler KH, Poeppl A, Ling V, Beyene J, Canty AJ, et al: Stem cell gene expression programs influence clinical outcome in human leukemia. Nat Med 17: 1086-1093, 2011.

3. Laurenti E, Doulatov S, Zandi S, Plumb I, Chen J, April C, Fan JB and Dick JE: The transcriptional architecture of early human hematopoiesis identifies multilevel control of lymphoid commitment. Nat Immunol 14: 756-763, 2013.

4. Tang DG: Understanding cancer stem cell heterogeneity and plasticity. Cell Res 22: 457-472, 2012

5. Hope KJ, Jin L and Dick JE: Acute myeloid leukemia originates from a hierarchy of leukemic stem cell classes that differ in self-renewal capacity. Nat Immunol 5: 738-743, 2004.

6. Sarry JE, Murphy K, Perry R, Sanchez PV, Secreto A, Keefer C, Swider CR, Strzelecki AC, Cavelier C, Récher C, et al: Human acute myelogenous leukemia stem cells are rare and heterogeneous when assayed in NOD/SCID/IL2R $\gamma$ c-deficient mice. J Clin Invest 121: 384-395, 2011.

7. Anderson K, Lutz C, van Delft FW, Bateman CM, Guo Y, Colman SM, Kempski H, Moorman AV, Titley I, Swansbury J, et al: Genetic variegation of clonal architecture and propagating cells in leukaemia. Nature 469: 356-361, 2011.

8. Park SY, Gönen M, Kim HJ, Michor F and Polyak K: Cellular and genetic diversity in the progression of in situ human breast carcinomas to an invasive phenotype. J Clin Invest 120: 636-644, 2010.

9. Lottaz C, Beier D, Meyer K, Kumar P, Hermann A, Schwarz J, Junker M, Oefner PJ, Bogdahn U, Wischhusen J, et al: Transcriptional profiles of CD133+ and CD133- glioblastoma-derived cancer stem cell lines suggest different cells of origin. Cancer Res 70: 2030-2040, 2010.

10. Proia TA, Keller PJ, Gupta PB, Klebba I, Jones AD, Sedic M, Gilmore H, Tung N, Naber SP, Schnitt S, et al: Genetic predisposition directs breast cancer phenotype by dictating progenitor cell fate. Cell Stem Cell 8: 149-163, 2011.

11. Jin L, Hope KJ, Zhai Q, Smadja-Joffe F and Dick JE: Targeting of CD44 eradicates human acute myeloid leukemic stem cells. Nat Med 12: 1167-74, 2006.

12. Jin L, Lee EM, Ramshaw HS, et al: Monoclonal antibodymediated targeting of CD123, IL-3 receptor alpha chain, eliminates human acute myeloid leukemic stem cells. Cell Stem Cell 5: 31-42, 2009.

13. Kikushige Y, Shima T, Takayanagi S, Urata S, Miyamoto T, Iwasaki H, Takenaka K, Teshima T, Tanaka T, Inagaki Y and Akashi K: TIM-3 is a promising target to selectively kill acute myeloid leukemia stem cells. Cell Stem Cell 7: 708-717, 2010.

14. Li Z, Lu J, Sun M, Mi S, Zhang H, Luo RT, Chen P, Wang Y, Yan M, Qian Z, et al: Distinct microRNA expression profiles in acute myeloid leukemia with common translocations. Proc Natl Acad Sci USA 105: 15535-15540, 2008.

15. Bousquet M, Harris MH, Zhou B and Lodish HF: MicroRNA mir-125b causes leukemia. Proc Natl Acad Sci USA 107: 21558-21563, 2010.

16. Blower PE, Chung JH, Verducci JS, Lin S, Park JK, Dai Z, Liu CG, Schmittgen TD, Reinhold WC, Croce CM, et al: MicroRNAs modulate the chemosensitivity of tumor cells. Mol Cancer Ther 7: 1-9, 2008.

17. de Leeuw DC, Denkers F, Olthof MC, Rutten AP, Pouwels W, Schuurhuis GJ, Ossenkoppele GJ and Smit L: Attentuation of microRNA-126 expression that drives CD34+38- stem/progenitor cells in acute myeloid leukemia leads to tumor eradication. Cancer Res 74: 2094-2105, 2014.

18. Guo W, Schubbert S, Chen JY, Valamehr B, Mosessian S, Shi H, Dang NH, Garcia C, Theodoro MF, Varella-Garcia M and Wu H: Suppression of leukemia development caused by PTEN loss. Proc Natl Acad Sci USA 108: 1409-1414, 2011.

19. Pece S, Tosoni D, Confalonieri S, Mazzarol G, Vecchi M. Ronzoni S, Bernard L, Viale G, Pelicci PG and Di Fiore PP: Biological and molecular heterogeneity of breast cancers correlates with their cancer stem cell content. Cell 140: 62-73, 2010.

20. Lim E, Vaillant F, Wu D, Forrest NC, Pal B, Hart AH, Asselin-Labat ML, Gyorki DE, Ward T, Partanen A, et al: Aberrant luminal progenitors as the candidate target population for basal tumor development in BRCA1 mutation carriers. Nat Med 15: 907-913, 2009.
21. Molyneux G, Geyer FC, Magnay FA, McCarthy A, Kendrick H, Natrajan R, Mackay A, Grigoriadis A, Tutt A, Ashworth A, et al: BRCA1 basal-like breast cancers originate from luminal epithelial progenitors and not from basal stem cells. Cell Stem Cell 7: 403-417, 2010.

22. Luo M, Zhao X, Chen S, Liu S, Wicha MS and Guan JL: Distinct FAK activities determine progenitor and mammary stem cell characteristics. Cancer Res 73: 5591-5602, 2013.

23. Li X, Lewis MT, Huang J, Gutierrez C, Osborne CK, Wu MF, et al: Intrinsic resistance of tumorigenic breast cancer cells to chemotherapy. J Natl Cancer Inst 100: 672-679, 2008.

24. Creighton CJ, Li X, Landis M, Dixon JM, Neumeister VM, Sjolund A, et al: Residual breast cancers after conventional therapy display mesenchymal as well as tumor-initiating features. Proc Natl Acad Sci USA 106: 13820-13825, 2009.

25. Reya $\mathrm{T}$ and Clevers $\mathrm{H}$ : Wnt signaling in stem cells and cancer. Nature 434: 843-850, 2005

26. Harrison H, Farnie G, Howell SJ, Rock RE, Stylianou S, Brennan KR, Bundred NJ and Clarke RB: Regulation of breast cancer stem cell activity by signaling through the Notch4 receptor. Cancer Res 70: 709-718, 2010.

27. Schott AF, Landis MD, Dontu G, Griffith KA, Layman RM, Krop I, Paskett LA, Wong H, Dobrolecki LE, Lewis MT, et al: Preclinical and clinical studies of gamma secretase inhibitors with docetaxel on human breast tumors. Clin Cancer Res 19: 1512-1524, 2013

28. Wang X, Kruithof-de Julio M, Economides KD, Walker D, Yu H, Halili MV, Hu YP, Price SM, Abate-Shen C and Shen MM: A luminal epithelial stem cell that is a cell of origin for prostate cancer. Nature 461: 495-500, 2009.

29. Aytes A, Mitrofanova A, Kinkade CW, Lefebvre C, Lei M, Phelan V, LeKaye HC, Koutcher JA, Cardiff RD, Califano A, et al: ETV4 promotes metastasis in response to activation of PI3-kinase and Ras signaling in a mouse model of advanced prostate cancer. Proc Natl Acad Sci USA 110: E3506-E3515, 2013.

30. Sun Y, Wang BE, Leong KG, Yue P, Li L, Jhunjhunwala S, Chen D, Seo K, Modrusan Z, Gao WQ, et al: Androgen deprivation causes epithelial-mesenchymal transition in the prostate: implications for androgen-deprivation therapy. Cancer Res 72: 527-536, 2012.

31. Lu TL, Huang YF, You LR, Chao NC, Su FY, Chang JL and Chen CM: Conditionally ablated Pten in prostate basal cells promotes basal-to-luminal differentiation and causes invasive prostate cancer in mice. Am J Pathol 182: 975-991, 2013.

32. Qin J, Liu X, Laffin B, Chen X, Choy G, Jeter CR, Calhoun-Davis T, Li H, Palapattu GS, Pang S, et al: The PSA(-/lo) prostate cancer cell population harbors self-renewing long-term tumor-propagating cells that resist castration. Cell Stem Cell 10: 556-569, 2012.

33. Jeter CR, Liu B, Liu X, Chen X, Liu C, Calhoun-Davis T, Repass J, Zaehres H, Shen JJ and Tang DG: NANOG promotes cancer stem cell characteristics and prostate cancer resistance to androgen deprivation. Oncogene 30: 3833-3845, 2011.

34. Liu C, Kelnar K, Liu B, Chen X, Calhoun-Davis T, Li H, Patrawala L, Yan H, Jeter C, Honorio S, et al: The microRNA miR-34a inhibits prostate cancer stem cells and metastasis by directly repressing CD44. Nat Med 17: 211-215, 2011.

35. Stephenson RA, Dinney CP, Gohji K, Ordóñez NG, Killion JJ and Fidler IJ: Metastatic model for human prostate cancer using orthotopic implantation in nude mice. J Natl Cancer Inst 84: 951-957, 1992.

36. Jeter CR, Badeaux M, Choy G, Chandra D, Patrawala L, Liu C, Calhoun-Davis T, Zaehres H,Daley GQ and Tang DG: Functional evidence that the self-renewal gene NANOG regulates human tumor development. Stem Cells 27: 993-1005, 2009.

37. Liu C, Kelnar K, Vlassov AV, Brown D, Wang J and Tang DG: Distinct microRNA expression profiles in prostate cancer stem/progenitor cells and tumor-suppressive functions of let-7. Cancer Res 72: 3393-3404, 2012.

38. Jin M, Zhang T, Liu C, Badeaux MA, Liu B, Liu R, Jeter C, Chen X, Vlassov AV and Tang DG: MicroRNA-128 suppresses prostate cancer by inhibiting BMI-1 to inhibit tumor-initiating cells. Cancer Res 74: 4183-4195, 2014.

39. Chan CH, Morrow JK, Li CF, Gao Y, Jin G, Moten A, Stagg LJ, Ladbury JE, Cai Z, Xu D, et al: Pharmacological inactivation of Skp2 SCF ubiquitin ligase restricts cancer stem cell traits and cancer progression. Cell 154: 556-568, 2013.

40. Singh SK, Hawkins C, Clarke ID, Squire JA, Bayani J, Hide T, Henkelman RM, Cusimano MD and Dirks PB: Identification of human brain tumour initiating cells. Nature 432: 396-401, 2004. 
41. Eyler CE, Wu Q, Yan K, MacSwords JM, Chandler-Militello D, Misuraca KL, Lathia JD, Forrester MT, Lee J, Stamler JS, et al: Glioma stem cell proliferation and tumor growth are promoted by nitric oxide synthase-2. Cell 146: 53-66, 2011.

42. Beier D, Hau P, Proescholdt M, Lohmeier A, Wischhusen J, Oefner PJ, Aigner L, Brawanski A, Bogdahn U and Beier CP. CD133(+) and CD133(-) glioblastoma-derived cancer stem cells show differential growth characteristics and molecular profiles. Cancer Res 67: 4010-4015, 2007.

43. Inda MM, Bonavia R, Mukasa A, Narita Y, Sah DW Vandenberg S, Brennan C, Johns TG, Bachoo R, Hadwiger P, et al: Tumor heterogeneity is an active process maintained by a mutant EGFR-induced cytokine circuit in glioblastoma. Genes Dev 24: 1731-1745, 2010.

44. Paola B, Barbara O, Lorenzo F, Daniel L, Giovanni B and Giuliana P: CD133 is essential for glioblastoma stem cell maintenance. Stem Cells 31: 857-869, 2013.

45. Zhou Y, Zhou Y, Shingu T, Feng L, Chen Z, Ogasawara M, Keating MJ, Kondo S and Huang P: Metabolic alterations in highly tumorigenic glioblastoma cells: preference for hypoxia and high dependency on glycolysis. J Biol Chem 286: 32843-32853, 2011.

46. Yuan S, Wang F, Chen G, Zhang H, Feng L, Wang L, Colman H, Keating MJ, Li X, Xu RH, et al: Effective elimination of cancer stem cells by a novel drug combination strategy. Stem Cells 31 : 23-34, 2013.

47. Heimberger AB, Suki D, Yang D, Shi W and Aldape K: The natural history of EGFR and EGFRvIII in glioblastoma patients. J Transl Med 3: 38, 2005.

48. Emlet DR, Gupta P, Holgado-Madruga M, Del Vecchio CA, Mitra SS, Han SY, Li G, Jensen KC, Vogel H, Xu LW, et al: Targeting a glioblastoma cancer stem-cell populations defined by EGF receptor variant III. Cancer Res 74: 1238-1249, 2014

49. Vermeulen L, De Sousa E, Melo F, van der Heijden M, Cameron K, de Jong JH, Borovski T, Tuynman JB, Todaro M, Merz C, et al: Wnt activity defines colon cancer stem cells and is regulated by the microenvironment. Nat Cell Biol 12: 468-476, 2010.

50. Glinsky GV, Berezovska O and Glinskii AB: Microarray analysis identifies a death-from-cancer signature predicting therapy failure in patients with multiple types of cancer. J Clin Invest 115: 1503-1521, 2005.

51. Kreso A, van Galen P, Pedley NM, Lima-Fernandes E, Frelin C, Davis T, Cao L, Baiazitov R, Du W, Sydorenko N, et al: Self-renewal as a therapeutic target in human colorectal cancer. Nat Med 20: 29-36, 2014

52. Du L, Rao G, Wang H, Li B, Tian W, Cui J, He L, Laffin B, Tian X, Hao C, et al: CD44-positive cancer stem cells expressing cellular prion protein contribute to metastatic capacity in colorectal cancer. Cancer Res 73: 2682-2694, 2013.
53. Gratio V, Loriot C, Virca GD, Oikonomopoulou K, Walker F, Diamandis EP, Hollenberg MD and Darmoul D: Kallikrein-related peptidase 14 acts on proteinase-activated receptor 2 to induce signaling pathway in colon cancer cells. Am J Pathol 179: 2625-2636, 2011.

54. Lee TK, Castilho A, Cheung VC, Tang KH, Ma S and Ng IO: $\mathrm{CD} 24(+)$ liver tumor-initiating cells drive self-renewal and tumor initiation through STAT3-mediated NANOG regulation. Cell Stem Cell 9: 50-63, 2011.

55. Lee TK, Cheung VC, Lu P, Lau EY, Ma S, Tang KH, Tong M, Lo J and $\mathrm{Ng}$ IO: Blockade of CD47-mediated cathepsin S/protease-activated receptor 2 signaling provides a therapeutic target for hepatocellular carcinoma. Hepatology 60: 179-191: 2014.

56. Teitz-Tennenbaum S, Wicha MS, Chang AE and Li Q: Targeting cancer stem cells via dendritic-cell vaccination. Oncoimmunology 1: 1401-1403, 2012.

57. Li Q, Lu L, Tao H, Xue C, Teitz-Tennenbaum S, Owen JH, Moyer JS, Prince ME, Chang AE and Wicha MS: Generation of a novel dendritic-cell vaccine using melanoma and squamous cancer stem cells. J Vis Exp 6: e50561, 2014.

58. Bertolini G, Roz L, Perego P, Tortoreto M, Fontanella E, Gatti L, Pratesi G, Fabbri A, Andriani F, Tinelli S, et al: Highly tumorigenic lung cancer CD133+ cells display stem-like features and are spared by cisplatin treatment. Proc Natl Acad Sci USA 106: 16281-16286, 2009.

59. Sarvi S, Mackinnon AC, Avlonitis N, Bradley M, Rintoul RC, Rassl DM, Wang W, Forbes SJ, Gregory CD and Sethi T: CD133+ cancer stem-like cells in small cell lung cancer are highly tumorigenic and chemoresistant but sensitive to a novel neuropeptide antagonist. Cancer Res 74: 1554-1565, 2014.

60. Yan H, Chen X, Zhang Q, Qin J, Li H, Liu C, Calhoun-Davis T, Coletta LD, Klostergaard J, Fokt I, et al: Drug-tolerant cancer cells show reduced tumor-initiating capacity: depletion of CD44 cells and evidence for epigenetic mechanisms. PLoS One 6: e24397, 2011.

61. Yu F, Yao H, Zhu P, Zhang X, Pan Q, Gong C, Huang Y, Hu X, Su F, Lieberman J and Song E: let-7 regulates self renewal and tumorigenicity of breast cancer cells. Cell 131: 1109-1123, 2007.

62. Emmink BL, Van Houdt WJ, Vries RG, Hoogwater FJ, Govaert KM, Verheem A, Nijkamp MW, Steller EJ, Jimenez CR, Clevers H, et al: Differentiated human colorectal cancer cells protect tumor-initiating cells from irinotecan. Gastroenterology 141: 269-278, 2011.

63. Dubrovska A, Elliott J, Salamone RJ, Kim S, Aimone LJ, Walker JR, Watson J, Sauveur-Michel M, Garcia-Echeverria C, Cho CY, et al: Combination therapy targeting both tumor-initiating and differentiated cell populations in prostate carcinoma. Clin Cancer Res 16: 5692-5702, 2010. 